\title{
A Novel Method to Enhance of Power Quality in Distribution System using IDVR
}

\author{
Shabbier Ahmed Sydu, Eswaraiah G
}

\begin{abstract}
The dynamic voltage trained worker (DVR) offers series compensation and better management resolution to voltage-sag drawback; as a results of the voltage restoration technique provides Active Power injection into the distribution system, to spice up active power at intervals the system ids done correct alternative of DVR in given network, considerably for mitigating long-duration voltage dips i.e. sag, and sag mitigation amount depends on the energy storage capability of the DVR. This paper prove higher answer in modeling the simulation of voltage sag compensation through Interline Dynamic Voltage trained worker (IDVR) and it provides some way to top off dc-link energy storage dynamically. The IDVR consists of the various\} DVRs connected to numerous distribution feeders within the power System. The DVRs within the IDVR system share common energy storage. one all told the DVR compensates for voltage sag showing throughout this feeder, the opposite DVRs top off the energy within the common dc-link dynamically. Thus, one DVR within the IDVR system works in voltage-sag compensation mode whereas the opposite DVRs within the IDVR system operate in constant power management mode. this system involves SPWM technologies to spice up the Doctor of Theology. The simulation results unit of measuring enclosed may additionally\} the operative principles of a DVR and shows the effectiveness and also the power of the projected IDVR system to spice up power quality
\end{abstract}

Index Terms: Power quality, Interline Dynamic voltage skilled worker [IDVR], structure electrical converter [MLI], THD, Voltage sag.

\section{INTRODUCTION}

When all is said in done, in vogue lattice has touchy a full pile, anyway they will have brought down their capacities or perhaps conclusion the system they're in underneath varied power give. Voltage varieties may even be named aggravations that create voltages underneath the face value, product known as voltage hangs, and unsettling influences that get yourself voltages over the evaluated worth, that get yourself voltage swells. Voltage list or plunge is shaped open as an unexpected decrease of give voltage down in the middle of ninetieth to 1 hundred workstations of appraised, trailed by a recuperation once a quick amount time. Atypical length of Voltage plunge is one $0 \mathrm{~ms}$ to 1 minute. Voltage droop can cause loss of creation in machine-controlled procedures since voltage list can trip an engine or cause its controller to breakdown. Voltage swell or rise is framed open as sudden expanding of offer voltage up in the middle of one hundred

Revised Version Manuscript Received on 16 September, 2019.

Shabbier Ahmed Sydu, Assistant Professor, Department of Electrical \& Electronics Engineering, TKR Engineering College, Hyderabad, Telangana, India.

(Email: youngminds.co@gmail.com)

Eswaraiah G, Assistant Professor, Department of Electrical \& Electronics Engineering, TKR Engineering College, Hyderabad, Telangana, India.

(Email: eshwar219@gmail.com) and tenth to one hundred and eightieth in RMS voltage at the fundamental recurrence with length from one $0 \mathrm{~ms}$ to 1 minute. move off degree high inductive burden or stimulating degree high gadget bank is causes sudden ascent in voltages known as swell in this manner there'll be control aggravations. Thus, DVR set in before of a fundamental burden will appropriately offer remedy at that particular of burden and individual DVR can't pay all through power unsettling influences. Voltage hang may even be a quick decline in RMS voltage blessing between [*fr1] cycles to numerous seconds. it continually brought about by flaws at interims the capacity network is relies upon its size and length. The voltage plunge size relies upon changed factors such unit issue sort and moreover the issue opposition.

Voltage sag is most significant PQ issues powerful the applications in trade is additionally adjusted and power is injected into the weaker bus. By injecting applicable voltage that compensates every purpose and Voltage magnitudes. DVR consists of a mixture of series and shunt converters, connected back to back, series device in each half, and a dc capacitance place in on the common dc link. The planned system is ready to mitigate long and considerably large voltage sags. . throughout this paper the operation and magnificence of MLI based totally DVR for voltage dip compensation is explained by providing higher analysis and magnificence of IDVR

\section{Interline Dynamic Voltage preserver (IDVR)}

The IDVR system have variety of DVRs in varied feeders, distributed a typical DC-link. A a pair of -line IDVR system conferred in Fig.1 employs a pair of DVRs ar coupled to 2 utterly totally different feeders. within which one in every of the DVRs compensates for voltage swell/sag created in IDVR system. These 2 DVRs operated severally looking on fault as a result of their settled at the common DC offer.

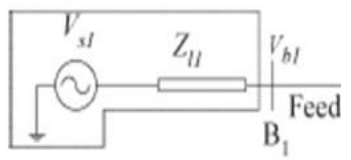

Common D

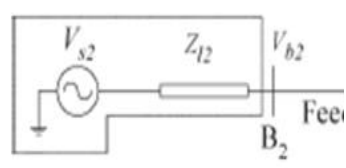

Fig 1: Single line diagram of an IDVR in a two-feeder 
system.

Fig.1. Single line diagram of IDVR for PQ problem that is Voltage swell/sag in a transmission system is shown as above fig 1. To understand the concept of operation of IDVR is explained by, If any voltage distortion in Feeder1, it would be compensated by opposite DVR present in healthier feeder section. The compensation and controlling of the proposed system is applied to the two feeders may be considered as two different independent sources. The voltage sources Vs1 and Vs2 presented in the power system are connected series with the line impedances and connected to the buses B1 and B2 as in Fig. 1 and Fig. 2. Illustrates the Phasor relation of DVR2 for active power transfer is shown fig 2 .

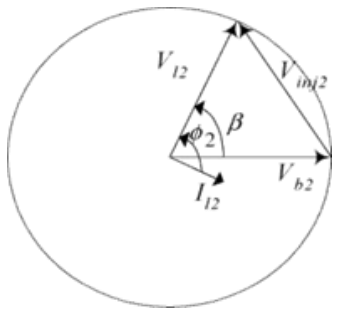

Fig. 2.Phasor relation of DVR2 for active power transfer.

The IDVR system operates in voltage-sag compensating mode whereas the selection DVRs operate in constant power flow mode to remain the dc-link voltage at a gaggle level. The phasor relation active power flow analysis of the two-feeder IDVR system shown in Fig. 1, it's assumed that DVR1 in Feeder one. If there is not any voltage sag, the load voltage of Feeder a mix of is capable the bus voltage Vb2. Even in sag things, the DVR2 got to be operated to satisfy this condition whereas provision real power to the common dc link. Hence, the locus of the V12 got to lie on a circle with radius capable the required magnitude of bus voltage $\mathrm{Vb} 2$, as shown in Fig. 2.The load voltage (V12) has Associate in Nursing advance purpose in time ? with affiliation the the provision supply voltage ( $\mathrm{Vb} 2)$, therefore on inject power to the dc link. With the help of a phasor diagram in Fig. 2, following power circulates among the feeders:

$$
P_{e x}=S_{l 2}\left[\cos \left(\varphi_{2}-\beta\right)-\cos \left(\varphi_{2}\right)\right]
$$

Fig.1. Single line outline of IDVR for PQ issue that is Voltage swell/hang in a transmission framework is appeared as above fig 1 . To comprehend the idea of activity of IDVR is clarified by, If any voltage contortion in Feeder1, it would be repaid by inverse DVR present in more beneficial feeder segment. The remuneration and controlling of the proposed framework is connected to the two feeders might be considered as two diverse autonomous sources. The voltage sources Vs1 and Vs2 exhibited in the power framework are associated arrangement with the line impedances and associated with the transports B1 and B2 as in Fig. 1 and Fig. 2. Represents the Phasor connection of DVR2 for dynamic power move is demonstrated fig 2 .

$$
\begin{gathered}
\mathrm{P}_{\text {ex } \max }=S_{l 2}[1-p f 2] \\
\mathrm{P}_{\text {ex }}=\mathrm{P}_{\text {DVR } 1}+\mathrm{P}_{1}
\end{gathered}
$$

\section{Where $\mathrm{Pl}=$ Power Loss}

The DVR is a series compensated FACTS device used to compensate voltage profile at the load side, irrespective of the supply changes load voltage must be same. It will done by IDVR in proposed system, it compensate the voltage sag in weaker feeder 1 with the help of Healthy feeder 2 [2]

\section{Control Strategy}

This paper presents designing and analysis of IDVR with 3-level inverter and SPWM based controller is designed with the help of MATLAB / Simulink. A simple design with best suited control strategy to mitigate the PQ problems and improve the robustness of the system. In addition, the performance of the designed DVR is developed under svariou sag conditions as shown in fig. 2 (a)

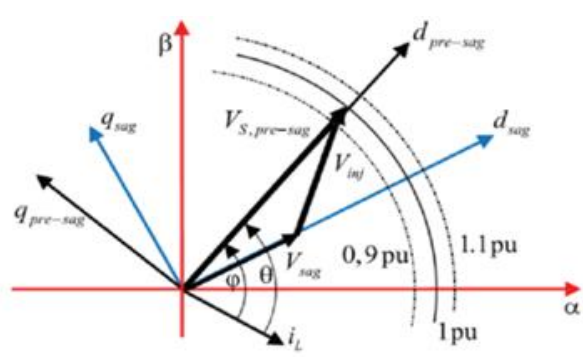

Fig 2 (a)

Any PQ issue raises at intervals the system voltage wave sort would possibly disturbed cause issues connected with the operation of electrical and electronic devices. Users wants constant AC provide, constant frequency and symmetrical voltage with constant RMS price to continue the assembly. This increasing interest to strengthen overall efficiency and eliminate variations among the trade have resulted countless troublesome components that ar sensitive to voltage disturbances. the quality PQ disturbances ar voltage sags, voltage swells, interruptions, section shifts, flickers, glitches, notches, harmonics and transients. Among the disturbances, voltage sag is taken under consideration the foremost severe since the sensitive plenty ar very in danger of temporary 
changes at intervals the voltage. The closed loop managementler with twin loop strategy worries throughout this work; the diagram voltage

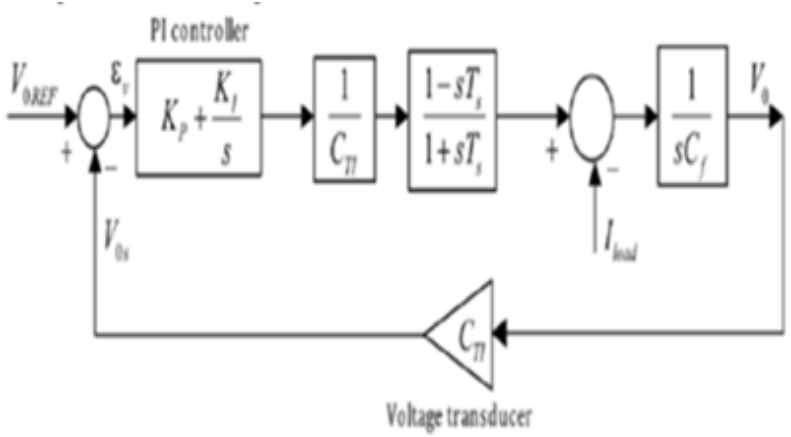

management closed loop system is as shown in Fig a 2(b management closed loop system is as shown in Fig a 2(b)

\section{Inverter Circuit:}

The v output voltage of the electrical converter is varied by victimisation voltage supply electrical converter (VSI). High frequency switch devices square measure used whereas planning of the electrical converter circuits. A VSI is energized by a continuing DC voltage supply, this supply of low internal resistivity at the input section. The output voltage is freelance of load current. In VSI output voltage variations comparatively less attributable to its capacitance, however it's a downside in dominant capacitance current. The 3 part PWMVSI is employed during this study as a result of its quality [3]. The output voltage is controlled by operational the electrical converter in correct switch sequence. MLI that offer bigger than 2 levels of voltage to understand power tool and fewer distorted. This paper presents a generalized structure electrical converter (3-level electrical converter) primarily based DVR topology with internal voltage reconciliation technique and MATLAB simulation was in deep trouble all different structure inverter such square measure five level and seven levels. this structure electrical converter like diode-clamped structure electrical converter may be used for reconciliation the load voltage through IDVR configuration. 3-level diode clamped electrical converter shown in Fig4 and part (a) switch states square measure shown in table 1 .

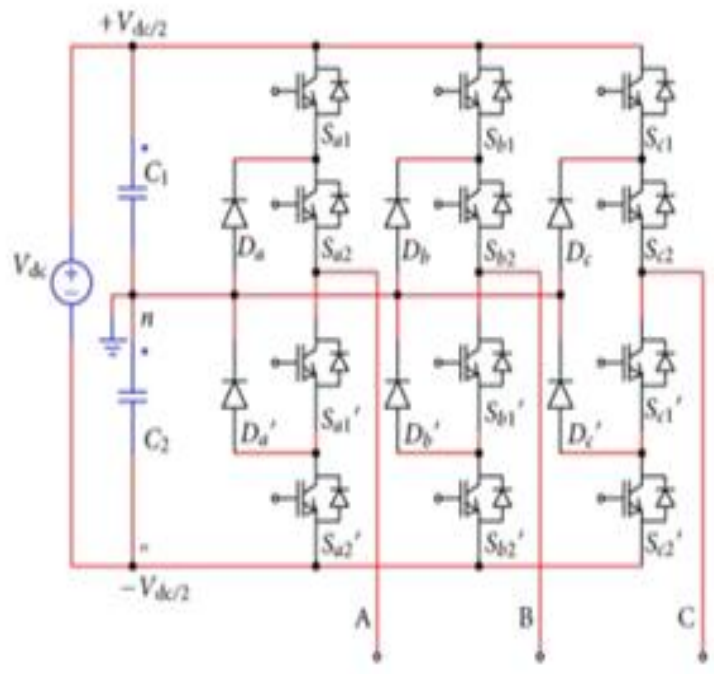

Fig 3: 3-level diode clamped multilevel inverter.
Table 1: Switching sequence on phase a of 3-level diode clamped inverter.

\begin{tabular}{|l|l|l|l|l|l|l|}
\hline S.No & Sa1 & Sa2 & Sa1' & Sa2' & $\begin{array}{l}\text { Switching } \\
\text { States }\end{array}$ & $\begin{array}{l}\text { Output } \\
\text { Phase } \\
\text { Voltage }\end{array}$ \\
\hline 1 & 1 & 1 & 0 & 0 & + & $+\mathrm{Vdc} / 2$ \\
\hline 2 & 0 & 1 & 1 & 0 & 0 & 0 \\
\hline 3 & 0 & 0 & 1 & 1 & - & $-\mathrm{Vdc} / 2$ \\
\hline
\end{tabular}

\section{Sinusoidal Pulse Width Modulation (SPWM)}

In SPWM instead of maintaining the breadth of all pulses the same as at intervals the case of multiple PWM, the dimension of each pulse is varied in proportion to the amplitude of a undulation evaluated at the same pulse. The distortion is reduced significantly compared to multiple PWM. The dq primarily based controller of DVR with 3-level converter is shown in fig.4

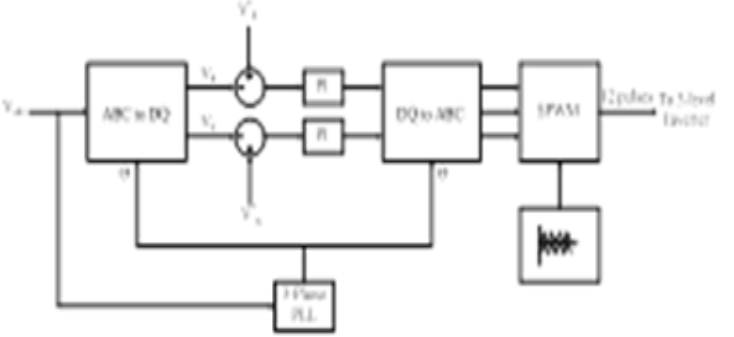

Fig. 4.Control of DVR with 3-Level Inverter based on DQ method.

Fig.1. Single line outline of IDVR for PQ issue that is Voltage swell/hang in a transmission framework is appeared as above fig 1. To comprehend the idea of activity of IDVR is clarified by, If any voltage contortion in Feeder1, it would be repaid by inverse DVR present in more beneficial feeder segment. The remuneration and controlling of the proposed framework is connected to the two feeders might be considered as two diverse autonomous sources. The voltage sources Vs1 and Vs2 exhibited in the power framework are associated arrangement with the line impedances and associated with the transports B1 and B2 as in Fig. 1 and Fig. 2. Represents the Phasor connection of DVR2 for dynamic power move is demonstrated fig 2 .

\section{MATLAB Simulation Results}

Two bus back to back connected IDVR System with correct control system arrangement as shown in Fig five. The rectifier- electrical converter system is shown as a system. The system model of full bridge electrical converter with a filter is additionally incontestable here to higher perceive of operation of IDVR. the road model of the IDVR system has shown Fig five. This presents the operation IDVR with the assistance of assorted multi level inverters and summarizes i.e. 3 Level, five Level and nine Levels with corresponding ThD values 


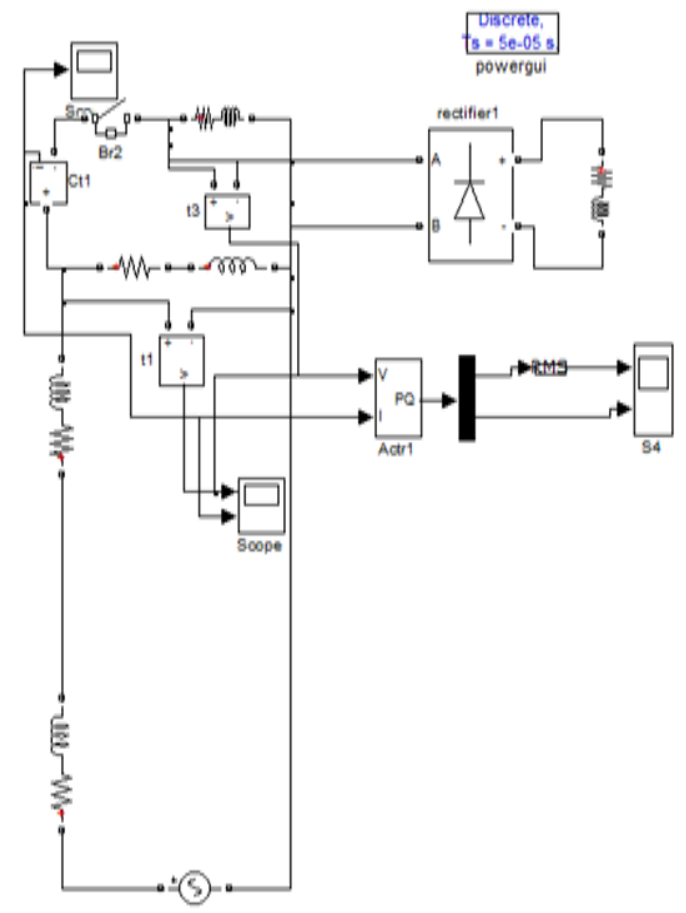

Fig. 5.Line model of Two bus system with out IDVR
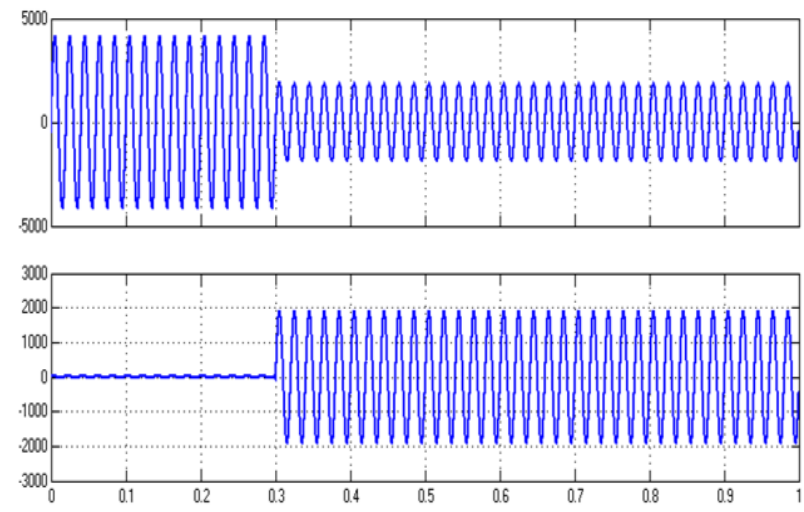

Fig. 6.Output voltage of Load-1 \&Load-2with out IDVR

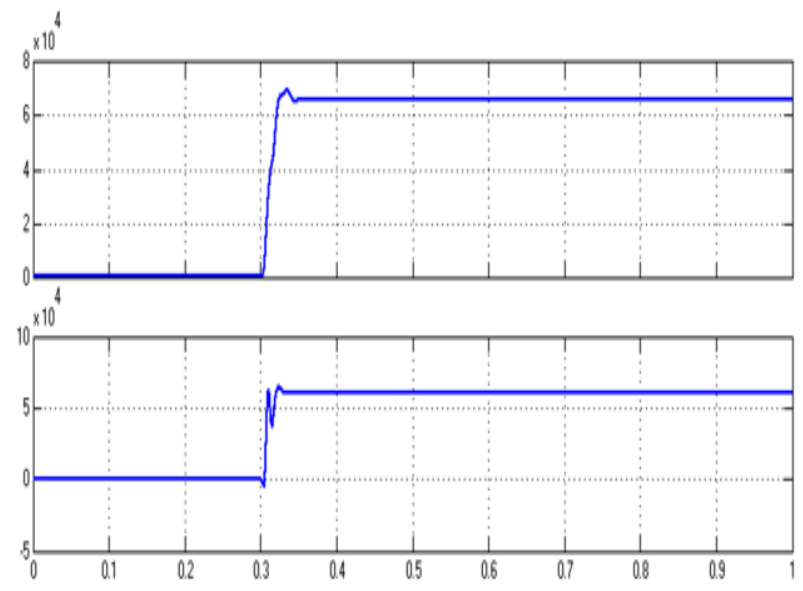

Fig. 7. Real \& Reactive powerwith out IDVR

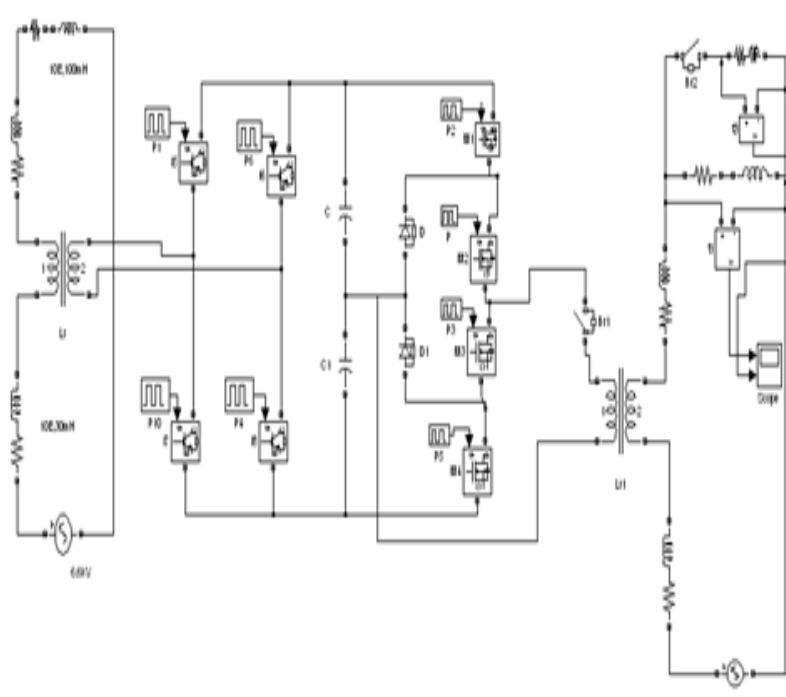

Fig. 8.Simulation Diagram for Three Level Inverter Based IDVR

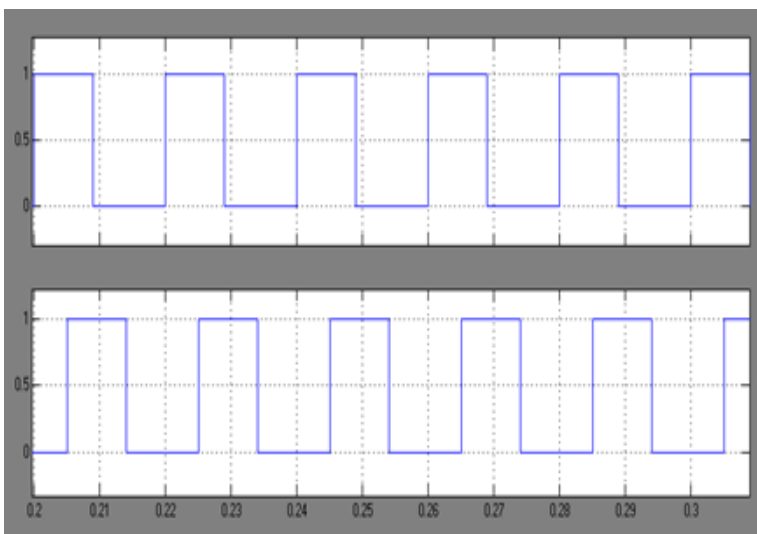

Fig. 9(a).Three Level InverterSwitches Driving Pulses

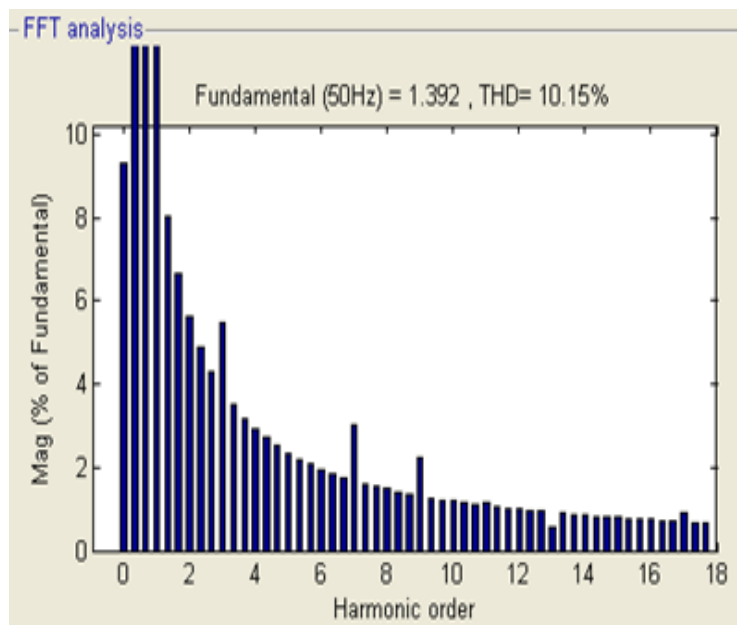

Fig. 9(b).Total Harmonic Distortion (THD) 


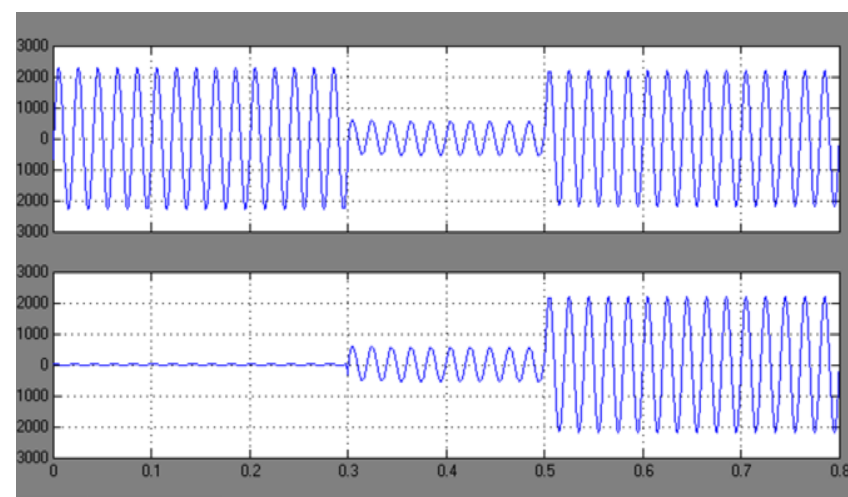

Fig. 10.Load 1 \& load-2 output Voltage of Three Level Inverter Based IDVR

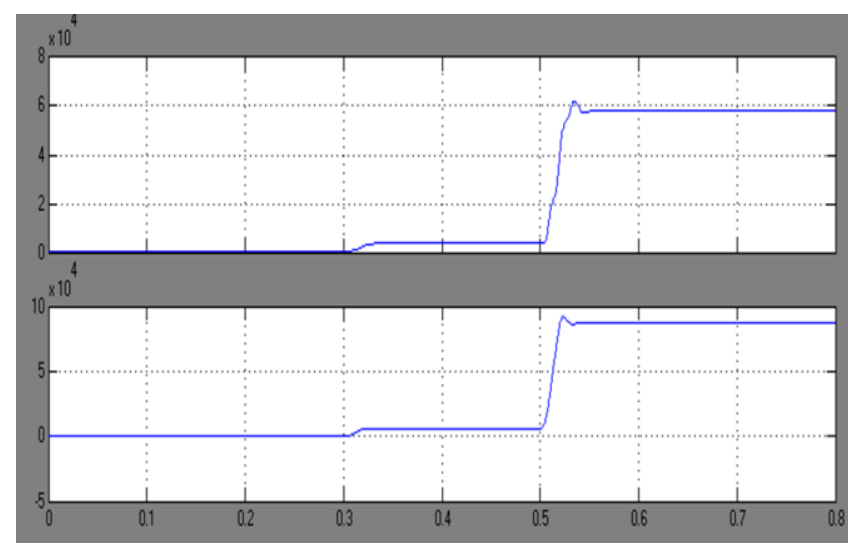

Fig. 11.Real \& Reactive powerof Three Level Inverter Based IDVR

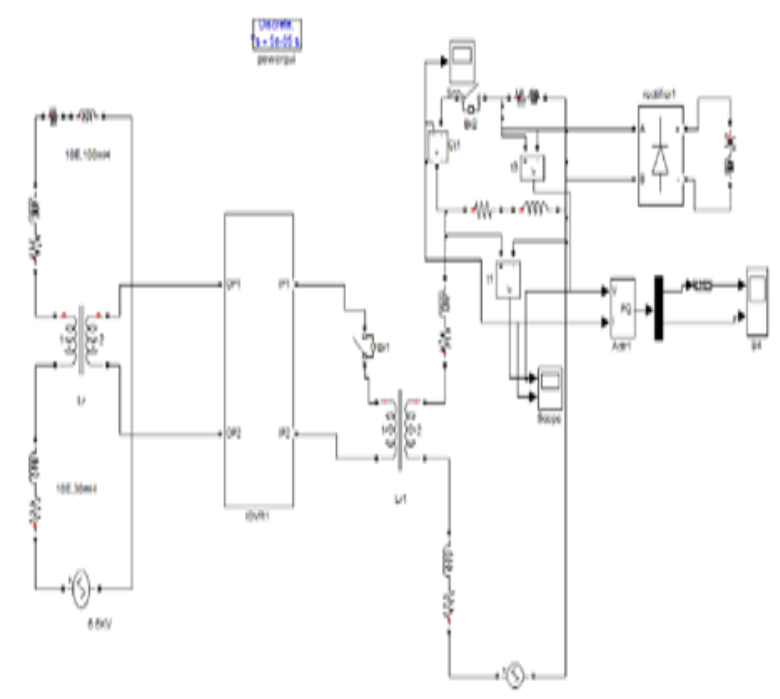

Fig. 12.Simulation Diagram for Seven Level Inverter Based IDVR

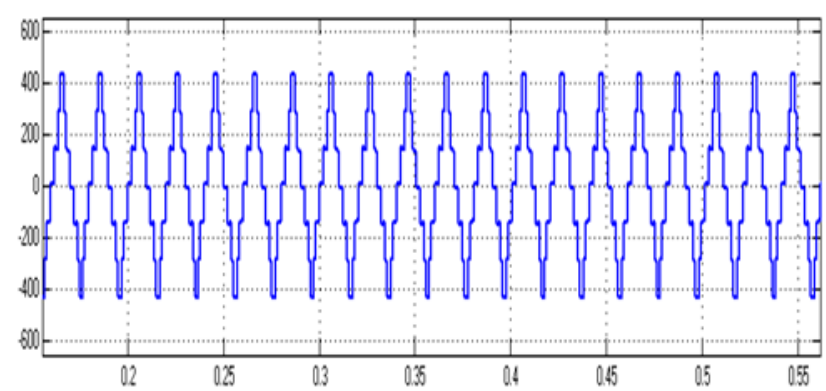

Fig. 13(a).Seven Level Inverter Switches Driving Pulses

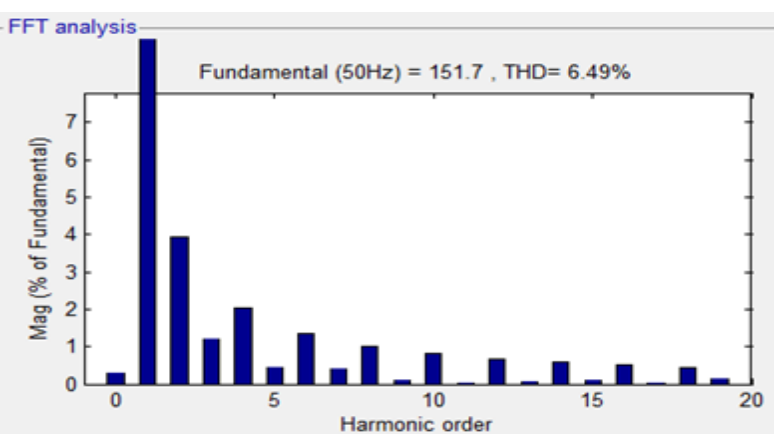

Fig. 13(b).Total Harmonic Distortion (THD)

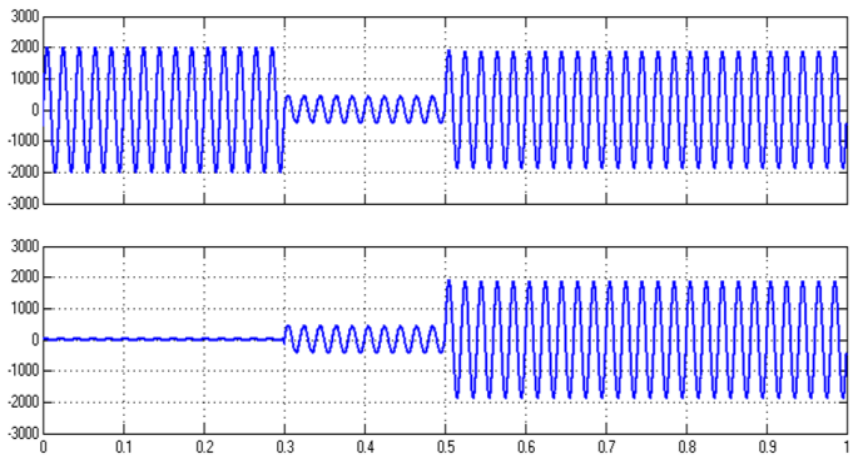

Fig. 14. Load 1 \& load-2 output Voltage of SevenLevel Inverter Based IDVR

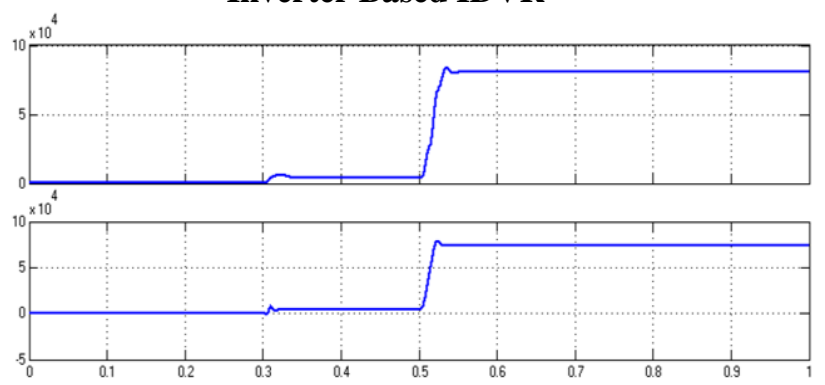

Fig. 15. Real \& Reactive power of Seven Level Inverter Based IDVR

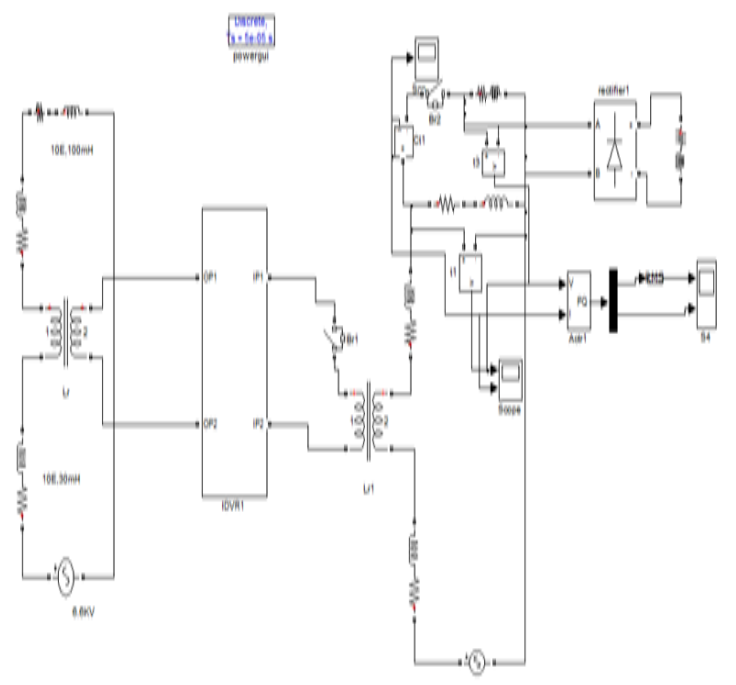

Fig. 16.Simulation Diagram for Nine Level Inverter Based IDVR.

Published By:

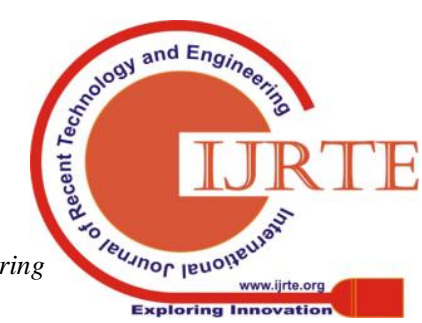




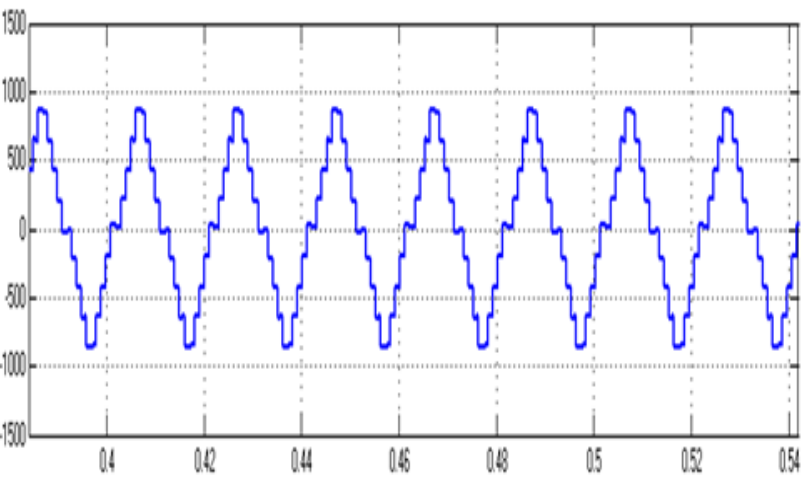

Fig. 17(a).Nine Level Inverter Switches Driving Pulses

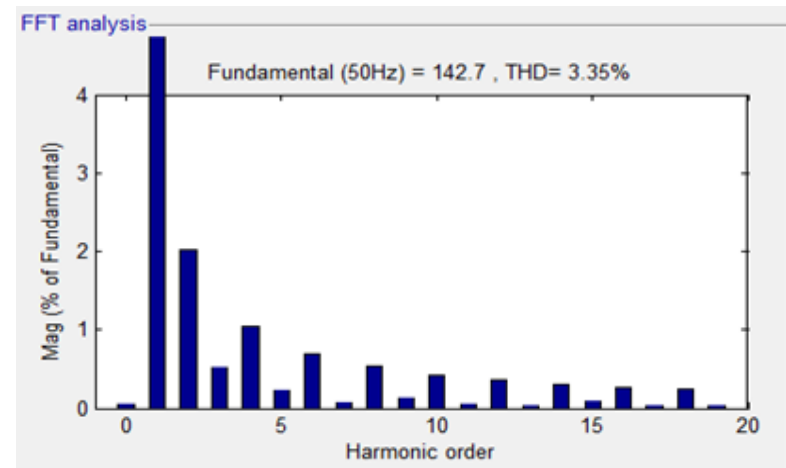

Fig. 17(b).Total Harmonic Distortion (THD)
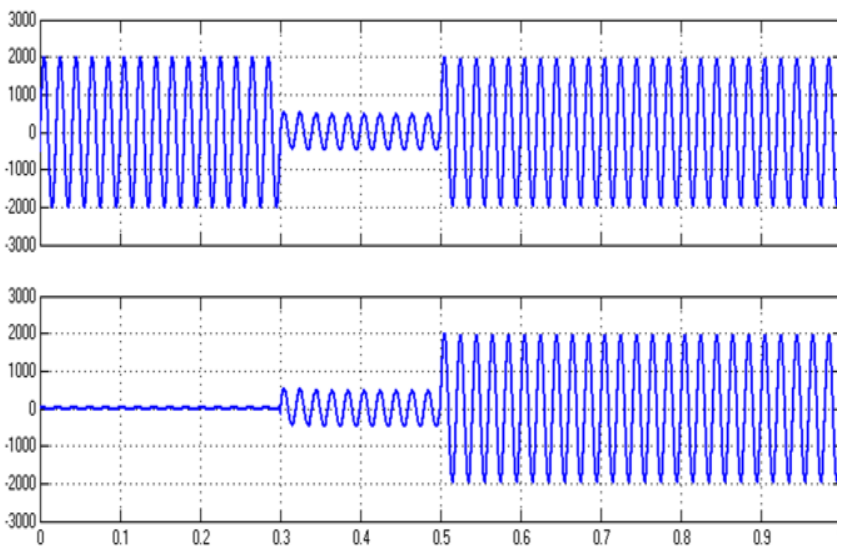

Fig. 18. Load 1 \& load-2 output Voltage of Nine Level Inverter Based IDVR

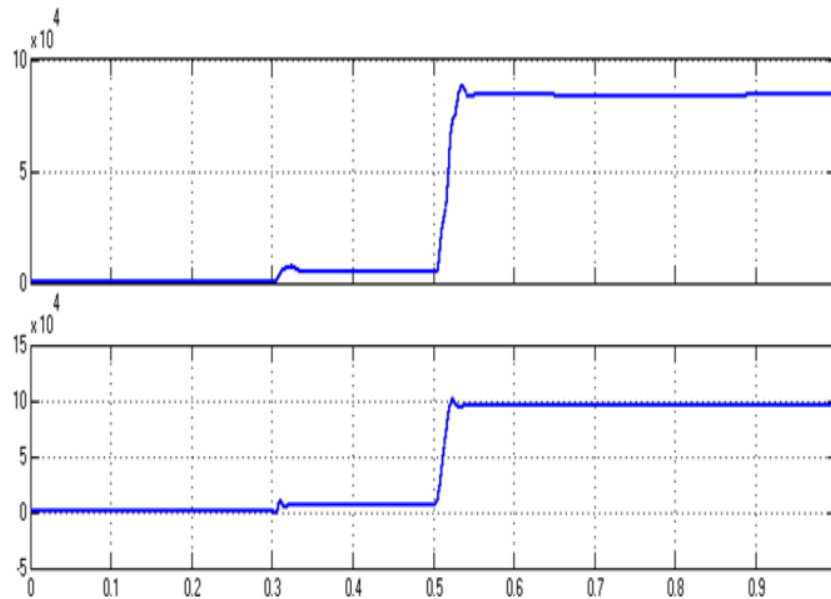

Fig. 19. Real \& Reactive power of Nine Level Inverter Based IDVR
Table-2 comparsion of Real, Reactive power and THD

\begin{tabular}{|l|l|l|l|}
\hline IDVR & $\begin{array}{l}\text { Real Power } \\
(\mathrm{MW})\end{array}$ & $\begin{array}{l}\text { Reactive Power } \\
(\mathrm{MVAR})\end{array}$ & THD \\
\hline 3-Level & 0.060 & 0.073 & $10.15 \%$ \\
\hline 7-Level & 0.081 & 0.085 & $6.49 \%$ \\
\hline 9-Level & 0.089 & 0.098 & $3.35 \%$ \\
\hline
\end{tabular}

\section{CONCLUSION}

In this works carries towards the performance of a IDVR in mitigating voltage sags/swells is explained with the assistance of MATLAB/ Simulink. The IDVR drives each balanced and unbalanced things with none difficulties and injects the acceptable voltage to keep up the load voltage inside the nominal voltage results load voltage constant and additionally discuss the each real and reactive power dominant between the lines. during this IDVR system robust bus inject the voltages to the corresponding week bus. This paper includes the performance behavior of IDVR for numerous Multi level inverters such area unit three, 7 and nine level. whereas range of levels will increase the content of harmonics within the distribution systems reduces step by step is mentioned and shown within the higher than table two. This work might extend additional for increasing range of levels and increasing range of Bus systems.

\section{REFERENCES}

1. D. Vilathgamuwa, S.S. Choi "A Novel Technique to Compensate Voltage Sags in Multiline Distribution System-The Interline Dynamic Voltage Restorer" IEEE Transactions on Industrial physics (Volume: fifty 3, Issue: 5, Oct. 2006 ).

2. D. MahindaVilathgamuwa, H. M. Wijekoon, and S. S. Choi: "A Novel Technique to Compensate Voltage Sags in Multiline Distribution System-The Interline Dynamic Voltage Restorer" IEEE TRANSACTIONS ON INDUSTRIAL physics, VOL. 53, NO. 5, October 2006, pp-1603-1611.

3. Shabbier Ahmed Sydu, Eswaraiah G: "Modeling and Analysis of a Dynamic Voltage preserver (DVR) for hardiness constraints with 3-Level converter and wiggly Pulse breadth Modulation (SPWM) based managementler" Jour of Adv analysis in dynamical Systems, Vol.10,07-Special issue,2018, pp-1972-1978.

4. P.Suresh, B.Baskaran: "Voltage Sag Compensation in Multiline Distribution System pattern system Controlled IDVR" IJAER,ISSN 0973-4562 Volume twelve, selection eight (2017) pp. 1576-1583.

5. S. SivaRanjani, K. Suresh "Hybrid interline dynamic voltage restoring and displacement issue dominant device for rising power quality of the distribution", Electrical, physics, and improvement Techniques (ICEEOT), International Conference on-24 Gregorian calendar month 2016.

6. M. Vilathgamuwa, A. A. D. R. Perera, and S. S. Choi, "Performance improvement of the dynamic voltage preserver with closed-loop load voltage and currentmode management," IEEE Trans. Power lepton., vol. 17, no. 5, pp. 824-834, Sep. 2002.

7. A. Ghosh and G. Ledwich, "Compensation of distribution system voltage pattern DVR," IEEE Trans. Power Del., vol. 17 , no. 4, pp. 1030-1036, Oct. 2002. 
8. Ahmed Elserougi Ahmed Hossam-Eldin "Investigation of Inter-Line Dynamic Voltage preserver with Virtual ohmic resistance Injection" 978-1-4244-5226-2/10/\$26.00 (C)2010 IEEE.

9. MajidMoradlou, and Hamid R. Karshenas. "Design Strategy for Optimum Rating selection of Interline DVR" IEEE Transactions on Power Delivery, Vol. 26, No. 1, Gregorian calendar month 2011.

10. Sandeep, R. K. Tripathi, and RishabhDevShukla"Voltage Stability Improvement in Power Systems pattern Facts Controllers: State-of-the- Art Review" 978-1-4244-8542-0/10/\$26.00 (02010 IEEE.

11. Bach graphic symbol. Khanh, J. Lian, B. Ramachandran, S. Srivastava, D. Cartes" Mitigating Voltage Sags due to DOL starting of three section Asynchronous Motors pattern Dynamic Voltage preserver (DVR)" 978-1-46731935-5/12/\$31.00 @2012 IEEE.

12. K. Beula Angel, G. Kaviarasy, S. Manjuparkavi, Mrs. B. Vishnupriya, "An Interline Dynamic Voltage preserver (IDVR)", International analysis Journal of Engineering and Technology (IRJET)-Feb-2018. 